\title{
A high-resolution integrated map of copy number polymorphisms within and between breeds of the modern domesticated dog
}

\author{
Thomas J Nicholas ${ }^{1}$, Carl Baker ${ }^{1}$, Evan E Eichler ${ }^{1,2}$ and Joshua M Akey ${ }^{1 *}$
}

\begin{abstract}
Background: Structural variation contributes to the rich genetic and phenotypic diversity of the modern domestic dog, Canis lupus familiaris, although compared to other organisms, catalogs of canine copy number variants (CNVs) are poorly defined. To this end, we developed a customized high-density tiling array across the canine genome and used it to discover CNVs in nine genetically diverse dogs and a gray wolf.

Results: In total, we identified 403 CNVs that overlap 401 genes, which are enriched for defense/immunity, oxidoreductase, protease, receptor, signaling molecule and transporter genes. Furthermore, we performed detailed comparisons between CNVs located within versus outside of segmental duplications (SDs) and find that CNVs in SDs are enriched for gene content and complexity. Finally, we compiled all known dog CNV regions and genotyped them with a custom aCGH chip in 61 dogs from 12 diverse breeds. These data allowed us to perform the first population genetics analysis of canine structural variation and identify CNVs that potentially contribute to breed specific traits.
\end{abstract}

Conclusions: Our comprehensive analysis of canine CNVs will be an important resource in genetically dissecting canine phenotypic and behavioral variation.

\section{Background}

The domestication of the modern dog from their wolf ancestors has resulted in an extraordinary amount of diversity in canine form and function. As such, dogs are poised to provide unique insights into the genetic architecture of phenotypic variation and the mechanistic basis of strong artificial selection. A number of canine genomics resources have been developed to facilitate genotype-phenotype inferences, including a high-quality whole genome sequence and a dense catalog of SNPs discovered in a wide variety of breeds [1-3]. These genomics resources have been successfully used to identify an increasing number of genes that influence hallmark breed characteristics such as size, coat texture, and skin wrinkling [4-6]. Additionally, SNP data has been used to investigate patterns of genetic variation within and between breeds, establish timing and geography of

\footnotetext{
* Correspondence: akeyj@uw.edu

'Department of Genome Sciences, University of Washington, 1705 NE Pacific, Seattle, WA. 98195, USA

Full list of author information is available at the end of the article
}

domestication, examine relatedness among breeds, and identify signatures of artificial selection [4,7-9].

In addition to SNPs, it is important to characterize additional components of canine genomic variation in order to comprehensively assess the genetic basis of phenotypic diversity. For example, structural variation in general, and copy number variants (CNVs) in particular, has emerged as an important source of genetic variation in a wide range of organisms including dogs [10-18]. Duplications and deletions of genomic sequence can have significant impacts on a wide range of phenotypes including breed-defining traits. For example, a duplication of a set of $F G F$ genes in Rhodesian and Thai Ridgebacks leads to the breeds characteristic dorsal hair ridge [19].

Although the FGF duplication provides a vivid example of the phenotypic consequences of structural variation in dogs, it remains unknown whether CNVs are an appreciable source of variation in morphological, behavioral, and physiological traits within and between breeds. Comprehensive discovery of structural variation
C Biomed Central

() 2011 Nicholas et al; licensee BioMed Central Ltd. This is an Open Access article distributed under the terms of the Creative Commons Attribution License (http://creativecommons.org/licenses/by/2.0), which permits unrestricted use, distribution, and reproduction in any medium, provided the original work is properly cited. 
in a diverse panel of breeds is an important first step in more systemically delimiting the contribution of CNVs to canine phenotypic variation. Previously, we used a customized aCGH chip to identify nearly $700 \mathrm{CNV}$ regions located in segmental duplications (SDs) [17]. However, SDs only cover approximately $5 \%$ of the dog genome and thus a large fraction of total genomic space was unexplored. An additional study using a genomewide tiling array from NimbleGen identified approximately $60 \mathrm{CNV}$ regions outside of SDs [10]. However, the low probe density $(\sim 1$ probe every $5 \mathrm{~kb})$, limited the number and size of CNVs that could be identified.

In an effort to more comprehensively interrogate the canine genome for CNVs, we used a high-density $(\sim 1$ probe every $1 \mathrm{~kb}$ ) genome-wide tiling array to discover additional CNVs in a panel of nine genetically and phenotypically diverse dogs. In total, we discover over 400 new CNV regions. Moreover, we designed a custom aCGH chip to genotype all known canine CNVs in 61 dogs from 12 diverse breeds, allowing the first population genetics analysis of structural variation in dogs to be performed. The comprehensive CNV resources that we have developed will be important tools in genetically dissecting canine phenotypic variation.

\section{Results and Discussion}

\section{Genome-wide identification of CNVs using a high-density} aCGH chip

We performed aCGH using a high-density tiling array in nine breeds (Table 1), a gray wolf, and a self-self hybridization. These nine breeds and gray wolf samples were previously studied using a custom array that exclusively targeted regions containing SDs [17]. In all of the aCGH hybridizations we used the same reference sample (a female Boxer distinct from Tasha, the Boxer used for generating the canine reference sequence), which was

Table 1 Summary of CNVs identified with the genomewide aCGH chip

\begin{tabular}{|c|c|c|c|c|c|}
\hline \multicolumn{6}{|c|}{ Number of CNVs } \\
\hline Breed & Total & Gain & Loss & Average Size (kb) & Genes \\
\hline Basenji & 109 & 45 & 64 & 54.9 & 114 \\
\hline Doberman Pinscher & 107 & 57 & 50 & 83.8 & 88 \\
\hline German Shepherd & 113 & 52 & 61 & 88.2 & 105 \\
\hline Labrador Retriever & 77 & 33 & 44 & 90.9 & 88 \\
\hline Pug & 97 & 44 & 53 & 62.3 & 74 \\
\hline Rottweiler & 88 & 30 & 58 & 92.6 & 65 \\
\hline Shetland Sheepdog & 86 & 35 & 51 & 123.5 & 91 \\
\hline Siberian Husky & 86 & 47 & 39 & 61.7 & 91 \\
\hline Standard Poodle & 109 & 37 & 72 & 64.6 & 127 \\
\hline Wolf & 136 & 79 & 57 & 86.5 & 127 \\
\hline Self & 0 & 0 & 0 & 0 & 0 \\
\hline Average & 101 & 46 & 55 & 80.9 & 97 \\
\hline
\end{tabular}

also the reference in our prior SD experiments [17]. The aCGH chip consists of over 2.1 million probes distributed across the genome (not including the uncharacterized chromosome, chrUn) with an average probe density of $1 \mathrm{~kb}$. CNVs were identified using a circular binary segmentation algorithm implemented in the program segMNT, part of NimbleGen's NimbleScan software package. These calls were filtered by $\log _{2}$ values and number of probes using an adaptive threshold algorithm where the specific filtering criteria were a function of the size of the CNV (see Methods).

We identified 1,008 CNVs in 403 unique CNV regions spanning $30.5 \mathrm{Mb}$ of genomic sequence (Table 1$)$. In the self-self hybridization, no CNVs were called using the same analysis and filters. The average number of CNVs per individual was 101, ranging from 86 (Shetland Sheepdog and Siberian Husky) to 136 (Gray Wolf). The average CNV size was approximately $81 \mathrm{~kb}$ (Table 1), and the largest CNV region was located on CFA 34 and spans 3.9 $\mathrm{Mb}$. In total, these $403 \mathrm{CNV}$ regions overlap or contain 401 protein coding genes. After assigning all genes PANTHER Molecular Function terms, we found that the most enriched gene classes are similar to those identified in SDs, namely, defense/immunity, and receptor genes, but also included oxidoreductase, protease, signaling molecule, and transporter genes (Additional file 1).

Figure 1 summarizes the location and characteristics of all known dog CNVs derived from this and previous studies [10,17]. In total, after merging closely spaced CNVs, 910 distinct CNV regions that cover over 49.8 $\mathrm{Mb}$ have been identified. Of these regions, 395 contain or overlap protein coding genes and 134 have been found in multiple experiments. Larger CNVs were more likely to be observed in multiple studies (average size of CNVs identified in multiple versus single studies was $220 \mathrm{~kb}$ versus $64 \mathrm{~kb}$, respectively). As expected, the uncharacterized chromosome (ChrUn), consisting of sequences that cannot be uniquely mapped to the genome, is particularly enriched for CNVs as it harbors approximately $65 \%$ of segmental duplications [17], which are hotspots of CNV formation.

\section{Comparison of SD vs Non-SD CNVs}

We used the same individuals and reference sample as in our previous study of CNVs in segmental duplications, providing an opportunity to directly compare characteristics of CNVs between SDs and non-SD regions (Table 2). While most CNVs were not associated with SDs, on average CNVs associated with SDs were much larger (160.1 kb vs $33.6 \mathrm{~kb}$; Table 2) resulting in the majority of CNV space to be associated with SDs (21.5 Mb or 70\%). Similarly, the majority of genic CNVs were also found in CNVs associated with SDs (66\%). 


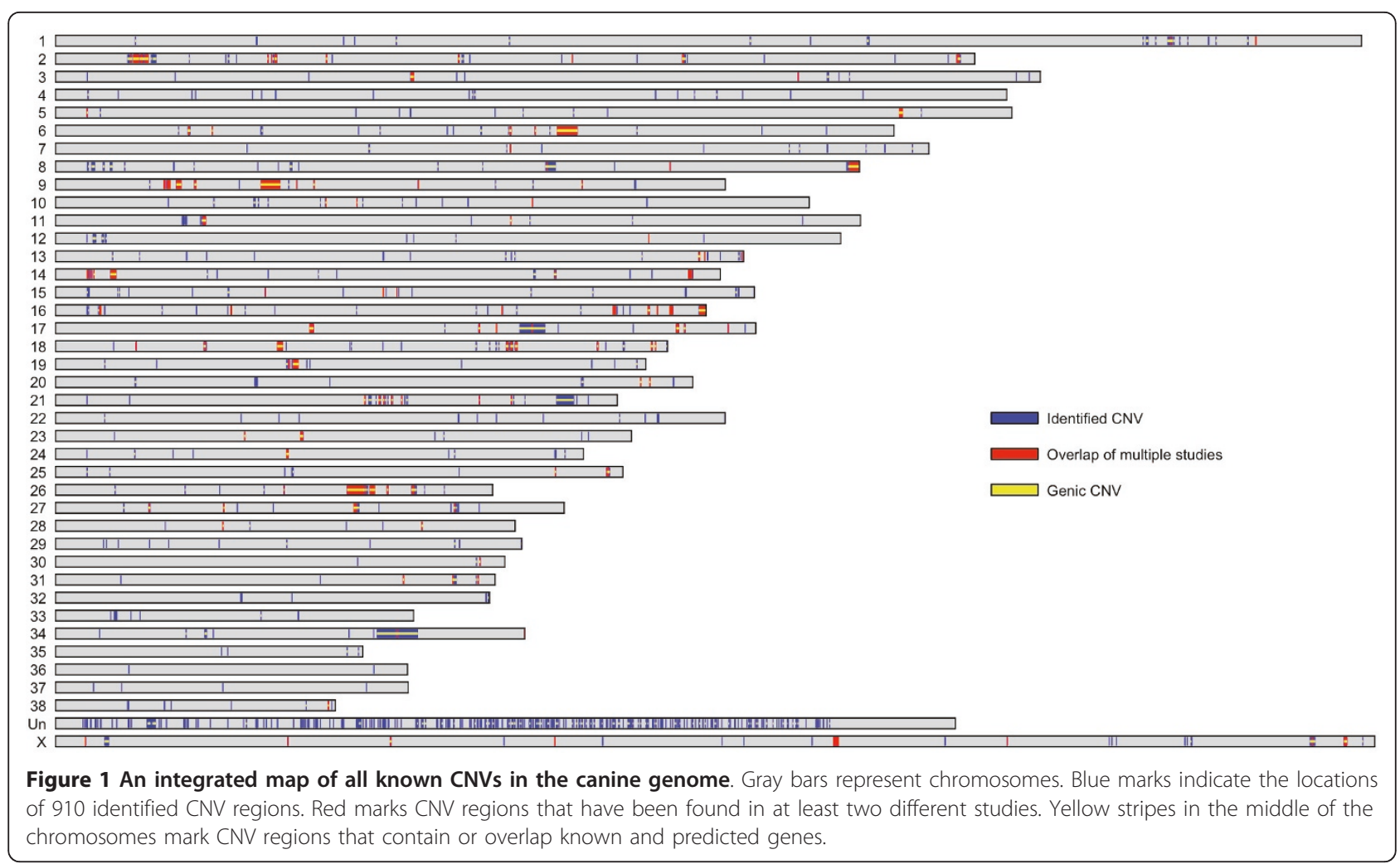

Of the 403 distinct CNV regions, 143 are present in multiple individuals and 260 were identified in a single individual. Interestingly, approximately $80 \%$ of these "singletons" are located outside of SDs (Table 2) as has been observed in humans [20-22]. Moreover, CNV complexity was markedly different between SD and non-SD CNVs. Specifically, we define CNV regions that exhibit both gains and losses in copy number within a single

Table 2 Comparison of CNVs located in SDs and outside of SDs

\begin{tabular}{|c|c|c|c|c|c|c|c|}
\hline Breed & CNV Location & Gain & Loss & Complex & Singletons & Average Size (kb) & Genes \\
\hline \multirow[t]{2}{*}{ Basenji } & SD & 17 & 22 & 3 & 4 & 173.0 & 82 \\
\hline & non-SD & 17 & 38 & 0 & 23 & 35.5 & 32 \\
\hline \multirow[t]{2}{*}{ Doberman Pinscher } & SD & 21 & 16 & 5 & 3 & 144.2 & 59 \\
\hline & non-SD & 22 & 25 & 0 & 15 & 40.8 & 29 \\
\hline \multirow[t]{2}{*}{ German Shepherd } & SD & 21 & 28 & 1 & 6 & 220.5 & 87 \\
\hline & non-SD & 26 & 29 & 0 & 22 & 40.2 & 18 \\
\hline \multirow[t]{2}{*}{ Labrador Retriever } & SD & 15 & 18 & 1 & 2 & 184.2 & 48 \\
\hline & non-SD & 14 & 23 & 0 & 14 & 91.8 & 40 \\
\hline \multirow[t]{2}{*}{ Pug } & SD & 11 & 18 & 4 & 7 & 223.1 & 42 \\
\hline & non-SD & 25 & 25 & 0 & 20 & 27.5 & 32 \\
\hline \multirow[t]{2}{*}{ Rottweiler } & SD & 9 & 27 & 1 & 4 & 222.2 & 46 \\
\hline & non-SD & 20 & 27 & 0 & 19 & 40.9 & 19 \\
\hline \multirow[t]{2}{*}{ Shetland Sheepdog } & SD & 15 & 24 & 0 & 3 & 339.2 & 75 \\
\hline & non-SD & 19 & 25 & 0 & 20 & 33.6 & 16 \\
\hline \multirow[t]{2}{*}{ Siberian Husky } & SD & 22 & 14 & 2 & 10 & 176.1 & 79 \\
\hline & non-SD & 15 & 21 & 0 & 15 & 52.2 & 12 \\
\hline \multirow[t]{2}{*}{ Standard Poodle } & SD & 13 & 26 & 1 & 7 & 215.6 & 87 \\
\hline & non-SD & 17 & 44 & 0 & 36 & 25.3 & 40 \\
\hline \multirow[t]{2}{*}{ Wolf } & SD & 34 & 25 & 3 & 16 & 207.7 & 95 \\
\hline & non-SD & 25 & 28 & 0 & 14 & 36.3 & 32 \\
\hline
\end{tabular}


individual as complex. While only 14 complex regions were identified, they are all from segmental duplications. These observations are consistent with the dynamic nature of SDs $[17,20-26]$, which are likely to harbor CNVs that are polymorphic within and between breeds.

\section{CNV genotyping using a custom aCGH chip}

To better understand how CNV variation is apportioned within and between breeds, we designed a custom 12plex NimbleGen aCGH chip and genotyped 61 dogs from 12 diverse breeds (Table 3) for all known canine CNVs (Figure 1). The average probe density was approximately $560 \mathrm{bp}$, and all of the hybridizations were performed with the same female Boxer used in previous aCGH experiments. We used a hidden Markov model implemented in the software package RJaCGH [27] to call CNVs for each CNV region in each sample (see Methods). The RJaCGH software package assigns a posterior probability to each aCGH probe as being in a gain, loss, or normal copy state. A summary of the posterior probabilities of each probe across all 61 individuals is shown in Figure 2.

Raw CNV calls from RJaCGH were filtered based on the number of data points, average posterior probabilities for probes in the putative CNV, and average $\log _{2}$ values (see Methods). Of the 892 regions studied, 665 (75\%) had at least one individual containing a CNV. Over 95\% of the CNV regions that appeared as monomorphic were previously identified in a breed not studied in the CNV genotyping panel; thus, failure to confirm CNVs in these regions is likely due to both individual or breed specific CNVs and false positives in previous CNV discovery experiments. As shown in Table 3, the average number of CNVs across all

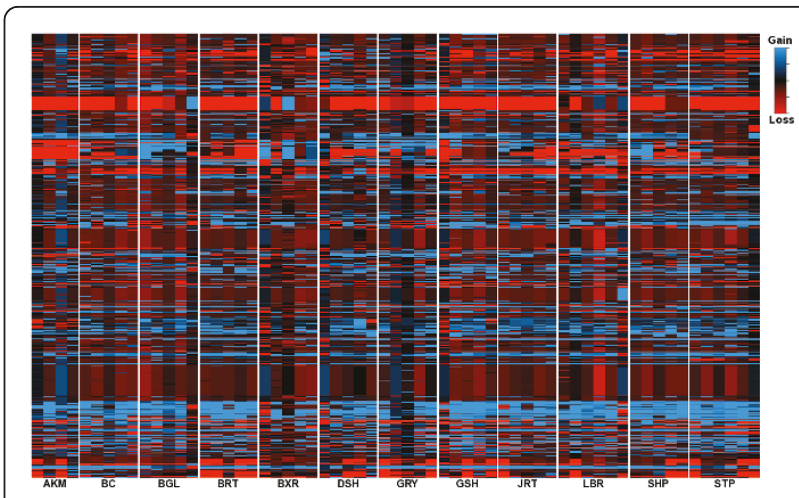

Figure 2 Heatmap representation of CNVs in all individuals. Columns represent individuals and rows represent a transformed measure of the posterior probability of each aCGH probe coming from a loss, normal copy, or gain state, denoted as $P_{\text {Loss, }} P_{\text {Normal, }}$ and $\mathrm{P}_{\text {Gain, }}$ respectively. Specifically, for each probe, the posterior probabilities of each state obtained from RJaCGH were converted into a single value by first dividing all three posterior probabilities by the largest value and then calculating a transformed score defined as $\left(P_{\text {Gain }}-P_{\text {Normal }}\right)$ - $\left(P_{\text {Loss }}-P_{\text {Normal }}\right)$, which results in a probe score that varies between -1 and 1 . The values of $-1,0$, and 1 correspond to the strongest evidence for loss, normal copy, and gains, respectively. Intermediate values reflect more uncertainty as to the state a given probe is in. Breeds are abbreviated as follows: Alaskan Malamute (AKM), Border Collie (BC), Beagle (BGL), Brittany (BRT), Boxer (BXR), Dachshund (DSH), Greyhound (GRY), German Shepherd (GSH), Jack Russell Terrier (JRT), Labrador Retriever (LBR), Shar Pei (SHP) and Standard Poodle (STP).

individuals was 187, ranging from 40 (in a Beagle and Greyhound) to 332 (in a Standard Poodle).

Before pursuing detailed population genetics inferences, we performed three analyses to assess data quality and false discovery rates. First, we performed three self-self hybridizations of a Boxer, Greyhound, and

Table 3 Summary of CNVs identified in each breed with the genotyping aCGH chip

\begin{tabular}{|c|c|c|c|c|c|c|c|c|c|}
\hline Breed & $\mathrm{N}^{\mathrm{a}}$ & Total CNVs & Average $^{b}$ & Range $^{c}$ & Average $\mathrm{H}_{\mathrm{e}}$ & Fixed Gains & Fixed Losses & Unique CNVs & Genic CNVs \\
\hline Alaskan Malamute & 4 & 406 & 188 & $86-306$ & 0.194 & 15 & 22 & 8 & 194 \\
\hline Beagle & 5 & 467 & 175 & $40-282$ & 0.201 & 9 & 0 & 4 & 185 \\
\hline Border Collie & 5 & 388 & 228 & $92-306$ & 0.244 & 16 & 11 & 10 & 223 \\
\hline Boxer & 5 & 403 & 133 & $72-244$ & 0.160 & 6 & 0 & 7 & 165 \\
\hline Brittany & 5 & 337 & 229 & $84-296$ & 0.227 & 25 & 5 & 2 & 195 \\
\hline Dachshund & 5 & 340 & 150 & $86-223$ & 0.171 & 6 & 4 & 4 & 168 \\
\hline German Shepherd & 5 & 382 & 201 & $144-219$ & 0.193 & 26 & 18 & 5 & 196 \\
\hline Greyhound & 5 & 394 & 156 & $40-267$ & 0.180 & 7 & 6 & 6 & 189 \\
\hline Jack Russell Terrier & 5 & 379 & 180 & $111-267$ & 0.185 & 27 & 6 & 2 & 189 \\
\hline Labrador Retriever & 6 & 409 & 179 & $119-254$ & 0.194 & 8 & 7 & 7 & 206 \\
\hline Shar Pei & 5 & 353 & 189 & $93-262$ & 0.191 & 22 & 4 & 3 & 170 \\
\hline Standard Poodle & 6 & 470 & 237 & $112-332$ & 0.242 & 35 & 1 & 18 & 230 \\
\hline
\end{tabular}

${ }^{a}$ Denotes the number of individuals studied.

b Average number of CNVs per individual

${ }^{\mathrm{c}}$ Indicates the range in the number of CNVs identified per individual within each breed. 
Shar-Pei. Using the same criteria to identify CNVs as described above, we called 0,1 , and 6 CNVs in the Shar-Pei, Boxer, and Greyhound, respectively. Thus, the self-self hybridizations suggest a low false discovery rate $(<5 \%)$. Second, we included 42 control regions on the genotyping aCGH chip selected from putatively single copy sequence defined from earlier CNV experiments [17]. Across all individuals, and thus a total 61 $\times 42=2,562$ total control regions, only $56 \mathrm{CNVs}$ were called (located in 14 distinct control regions), which also suggests a low false discovery rate. Note, it is plausible that genuine CNVs exist in some of these putative single copy control sequences, which were not observed in previous studies that examined a smaller number of individuals. Indeed, Monte Carlo simulations demonstrate that the expected number of control regions to harbor a $\mathrm{CNV}$ given 56 false positives is 31 (standard deviation $=2$ ), suggesting that the observed patterns of CNVs in control regions are more clustered than expected by chance and hence some may be genuine CNVs. Third, three of the individuals included in the genotyping panel (a German Shepherd, Labrador Retriever, and Standard Poodle) were also previously interrogated for CNVs with the SD [17] and 2.1 chips (described above). The average overlap between CNVs called in the previous aCGH experiments and the genotyping chip across all three samples was $74.9 \%$. To interpret the observed amount of overlap, we performed extensive simulations that recapitulate characteristics of the three aCGH chips and distribution of $\log _{2}$ values (see Methods). The observed overlap was similar to the simulated data (average overlap 71.9\%, with a 95\% confidence interval of 70.9-73.2\%), and the discordances are primarily a result of different probe densities across chips that influences the power to detect CNVs. Overall, these three analyses suggest the CNV genotype data is of high quality.

Furthermore, we also examined whether CNV calls were more concordant between the genotyping chip and the SD chip or between the genotyping chip and NimbleGen 2.1 tiling array. In general, the concordances were similar, but higher for CNVs initially discovered on the SD chip (0.78) than CNVs discovered on the NimbleGen 2.1 tiling chip (0.71). Moreover, as expected, larger CNVs $(>=100 \mathrm{~kb})$ were more concordant (81.6\%) than smaller (<100 kb) CNVs (74.9\%).

\section{Patterns of CNV diversity within breeds}

We estimated approximate allele frequencies for each breed and for each CNV using a simple EM algorithm [28] (see Methods). From these allele frequencies, we calculated the expected heterozygosity $\left(\mathrm{H}_{\mathrm{e}}\right)$ for each breed at every polymorphic CNV region, and the average $\mathrm{H}_{\mathrm{e}}$ for each breed is shown in Table 3. As expected from SNP and sequence data $[1,3]$, Boxers were the least diverse breed studied and Border Collies were the most diverse breed (Table 3). Interestingly, we observe a significant difference $\left(\mathrm{p}<10^{-5}\right)$ in the average $\mathrm{H}_{\mathrm{e}}$ between CNVs from SDs and CNVs not from SD (Figure 3) in all breeds, consistent with the dynamic nature of SDs leading to increased segregating variation.

To better understand how CNVs contribute to within breed diversity, we searched for $\mathrm{CNV}$ regions that exhibited high levels of heterozygosity. Interestingly, 45 regions were identified that exhibited high diversity in one or more breeds $\left(\mathrm{H}_{\mathrm{e}}>0.6\right)$. For example, a CNV region on CFA12 was identified in the Standard Poodle, which contains a number of genes, such as PSORS1C2, $C D S N$, and CCHCR1, that are associated with various epithelial processes and skin disorders (Figure 4).

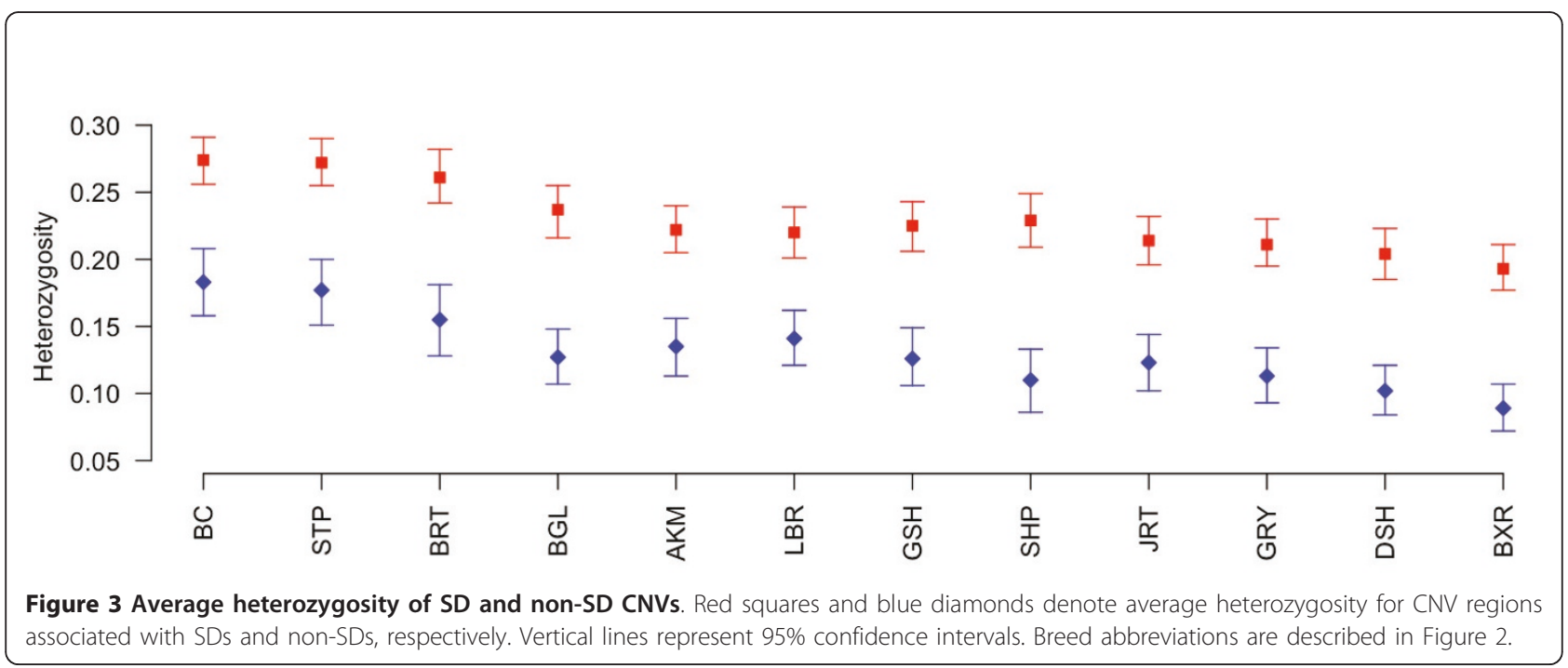




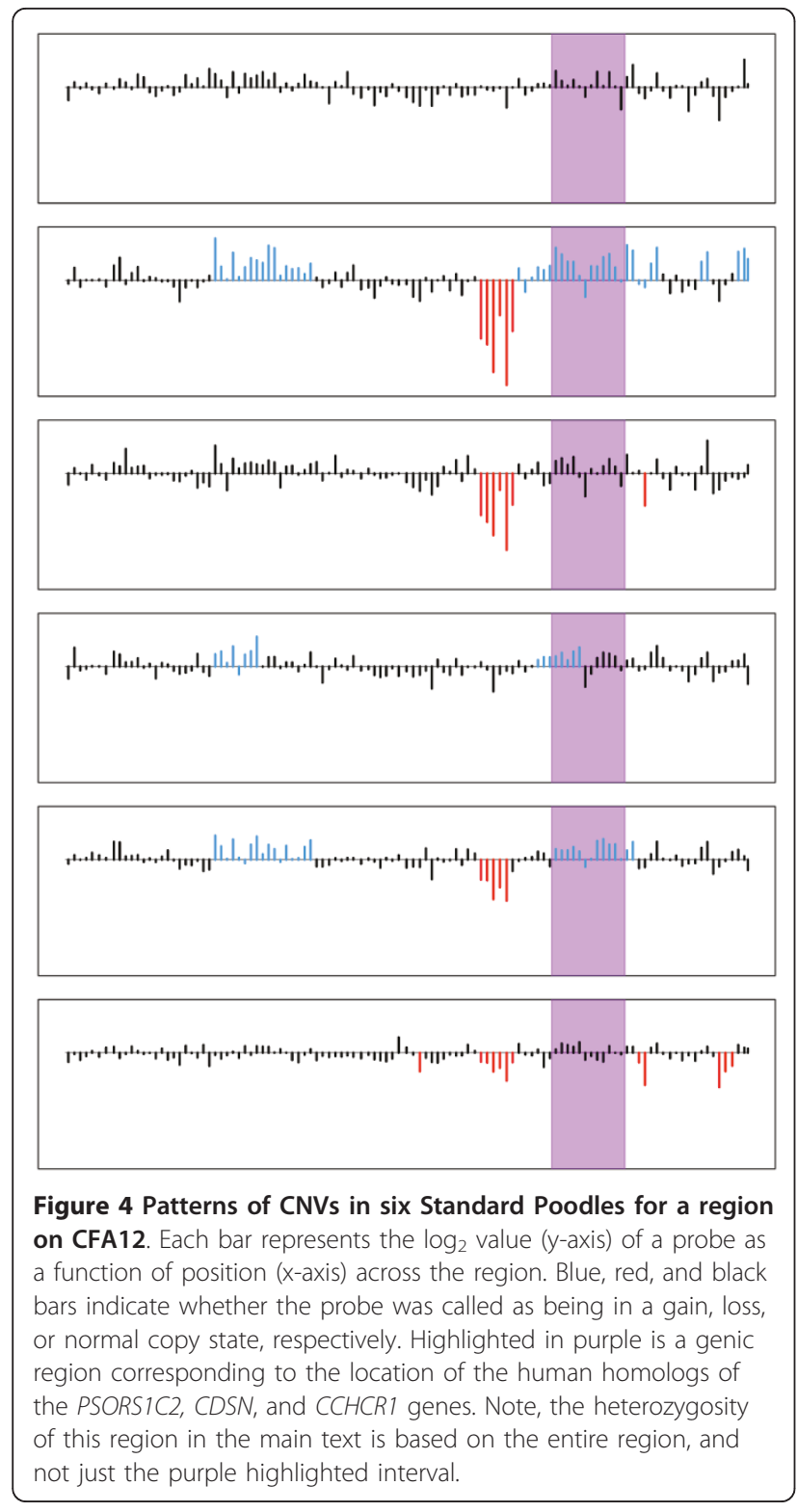

Standard Poodles are a breed marked with common occurrences of skin disorders or disorders with epithelial symptoms such as Cushing's disease (hyperadrenocorticism) $[29,30]$ and Sebaceous adenitis [31,32]. Additionally some skin disorders, such as psoriasis in humans, have been associated with copy number polymorphisms [33]. Thus, PSORS1C2, CDSN, and CCHCR1 are excellent candidates to pursue in future association studies of skin phenotypes in Standard Poodles. Furthermore, a topoisomerase gene, TOP $3 B$, involved in the cutting of DNA strands during transcription and recombination [34], was also found to be polymorphic in six breeds (Alaskan Malamute, Border Collie, Brittany, Labrador Retriever, Shar Pei, and Standard Poodle).

\section{Patterns of CNV diversity between breeds}

To better understand patterns of $\mathrm{CNV}$ variation between breeds, we calculated $\mathrm{F}_{\mathrm{ST}}$ for each polymorphic $\mathrm{CNV}$ region. The distribution of $\mathrm{F}_{\mathrm{ST}}$ across all $\mathrm{CNV}$ regions is shown in Figure 5, which ranges from 0.028 to 0.86 . The average $\mathrm{F}_{\mathrm{ST}}$ is 0.168 , which is comparable, although slightly lower than estimates of $\mathrm{F}_{\mathrm{ST}}$ in SNP data $[4,8]$. No significant difference in $\mathrm{F}_{\mathrm{ST}}$ was detected between SD and non-SD CNVs ( $p>0.05$ ). A number of interesting genes exist among the top 50 most differentiated $\mathrm{CNV}$ regions that may be relevant to phenotypic variation between breeds, such as $A T B F 1$, a zinc finger transcription factor that regulates neuronal and muscle development [35] and NKAIN2, which is associated with susceptibility to lymphoma [36], the most common form of canine cancer [37].

In addition, we also identified CNVs where all individuals within one or more breeds carried a duplication or deletion, but was absent in at least one of the remaining breeds. In total, 49 such regions exhibiting this pattern were identified (Figure 6, Additional file 2), 21 of which overlap the top 50 most differentiated CNVs described above. A number of these divergent regions possessed genes that potentially contribute to phenotypic differences between breeds such as development (OBSCN, NOTCH2, and NKD2), neuronal processes (TNFRSF1B and ATBF1), olfaction (OR4S2, OR4C30, and OR52B4), and metabolism (HMGCS2).

\section{Conclusions}

In summary, we have compiled the most comprehensive catalog of canine structural variation described to date. Moreover, we examined patterns of variation for all known canine CNVs in a diverse panel of 12 breeds, providing the first insight into how structural variation is apportioned within and between breeds. Interestingly, we found high levels of CNV diversity within breeds, suggesting that structural variation may be an important source of genetic variation contributing to within breed patterns of phenotypic diversity. Moreover, our data is consistent with a high rate of de

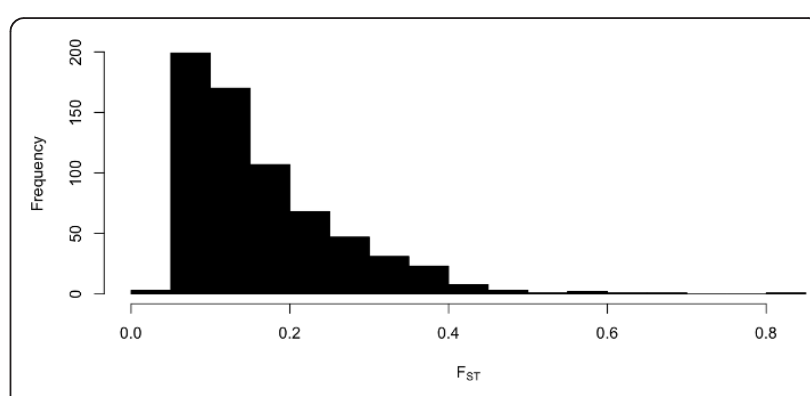

Figure 5 Distribution of $\mathrm{F}_{\mathrm{ST}}$ from all polymorphic $\mathrm{CNV}$ regions 


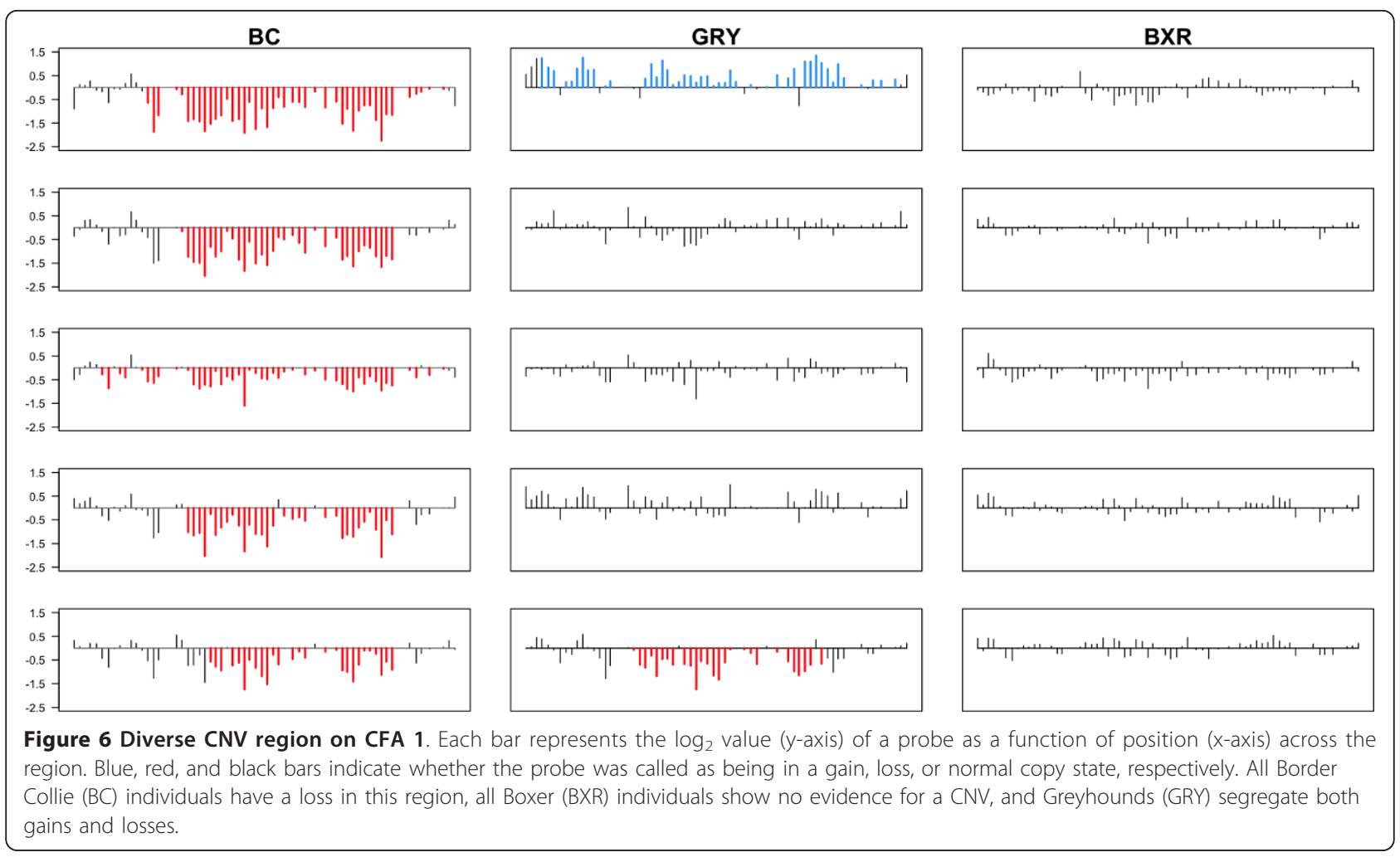

novo CNV formation within breeds. We anticipate that the CNV resources developed in this work will complement existing genome-wide panels of SNP markers $[1,3,9]$ by providing the foundation for future association studies to delimit how structural variation contributes to canine phenotypic variation and disease susceptibility.

\section{Methods}

\section{DNA samples}

For the genome-wide tiling aCGH experiments, a single individual from the following breeds was used: Basenji, Doberman, German Shepherd, Labrador Retriever, Pug, Shetland Sheepdog, Siberian Husky, Standard Poodle, Rottweiler, and a Grey Wolf. Samples used in the genotyping aCGH experiments included the following breeds: Alaskan Malamute, Beagle, Border Collie, Boxer, Brittany, Dachshund, German Shepherd, Greyhound, Jack Russell Terrier, Labrador Retriever, Shar Pei, and Standard Poodle. A total of 3 "self-self" hyrbidizations were performed using the female Boxer reference, a Greyhound, and Shar Pei. DNA quality of all samples was assessed by taking OD260/280 and OD260/230 readings using a nanospectrometer.

\section{aCGH and CNV identification}

The high density aCGH chip was designed and produced by NimbleGen http://www.NimbleGen.com, and included 2,164,508 oligonucleotide probes with an average probe spacing of $1050 \mathrm{bp}$. All genomic DNA samples were sent to NimbleGen who performed the hybridizations. In all cases a female Boxer was used as the reference sample. Each hybridization was initially subjected to segmentation using the CGH-segMNT program within the NimbleScan software package. Segments were further partitioned if there was a gap greater than $50 \mathrm{~kb}$ between adjacent probes. Furthermore, segments within $5 \mathrm{~kb}$ of one another and with consistent $\log _{2}$ ratios (either both positive or both negative) were merged together to form a new segment. To define segments corresponding to gains and losses, we developed an adaptive threshold algorithm that takes advantage of the observation that segments with more data points require smaller changes in $\log _{2}$ ratios to be reliably called as a gain or loss whereas segments with fewer data points require larger magnitudes of $\log _{2}$ ratios to be accurately called as a gain or loss. We trained our algorithm on the self-self hybridization to identify parameters resulting in a low false discovery rate. Specifically, if a segment contained 5-10 data points, 11-100, or $>100$ data points, we required an average $\log _{2}$ ratio that was 3,2 , and 1 standard deviations or greater from the mean, respectively, to be retained. Thus, a minimum of five probes was required to call a CNV. All aCGH data has been submitted to GEO http://www. ncbi.nlm.nih.gov/geo/ under accession number GSE26170. 


\section{CNV genotyping}

A custom aCGH genotyping chip was developed with NimbleGen using the CamFam2.0 assembly. The chip contains 12 individual lanes, each spotted with 136,929 oligonucleotide probes with a mean probe spacing of approximately $560 \mathrm{bp}$. These probes were primarily designed to tile over all previously identified CNVs including the $678 \mathrm{CNV}$ regions identified in segmental duplications [17], $403 \mathrm{CNV}$ regions identified from a genome-wide CNV detection survey using the NimbleGen 2.1 tiling arrays, and $60 \mathrm{CNV}$ regions from a separate genome-wide study [10]. In addition, 42 putative single copy control regions that had never before been found to contain CNVs and were not associated with segmental duplications were included. Finally, 1,095 additional regions were included on the chip, which were derived from lower confidence CNV calls. Note, these CNV regions were excluded in all analyses described in this manuscript, but information about them is provided in Additional files 3 and 4 . Coordinates from all these regions were merged and covered with aCGH probes. Hybridizations of 61 individuals from 12 different breeds were performed using a common female Boxer as a reference sample. Additionally, three self-self hybridizations were also performed. Breeds were randomized across chips to mitigate confounding factors.

The raw $\log _{2}$ ratios were first normalized by loess regression. Next, we fit linear models to the residuals of the loess regression to account for spot position and chip number. For all samples, individual probes were grouped into sets of five continuous probes (unless adjacent probes were more than $5 \mathrm{~kb}$ apart) and their $\log _{2}$ value was averaged. The average $\log _{2}$ values were then called for CNVs using a reversible jump hidden Markov Model implemented in the software RJaCGH [27]. The output of RJaCGH consists of a state call for each probe (i.e., gain, normal copy, and loss) and the posterior probability of being in each state. Using the self-self hybridizations, adaptive thresholds were established to filter these raw CNV calls based on the number of data points, average posterior probabilities for probes in the putative CNV, and average $\log _{2}$ value across probes in a putative CNV. Specifically, for segments consisting of three to five averaged data points (corresponding to approximately $8.4-14 \mathrm{~kb}$ ), we required a posterior probability greater than 0.75 and a $\log _{2}$ value equal to the mean $\pm 0.5 *$ standard deviation of all $\log _{2}$ values (note, plus for gains and minus for losses). If the segment consisted of $>5$ averaged data points (corresponding to a minimum size of approximately $16.8 \mathrm{~kb}$ ), we retained RJaCGH CNV calls with a posterior probability $\geq 0.6$. All unique $\mathrm{X}$-linked $\mathrm{CNVs}$ called as deletions in male dogs were removed since the reference was a female dog.

\section{Simulations}

Simulations were performed to interpret the observed amount of overlap between CNVs for the German Shepherd, Labrador Retriever, and Standard Poodle samples, which were analyzed on multiple chip platforms. The aCGH designs considered included the custom segmental duplication chip [17], the genome-wide 2.1 million feature chip, and the genotyping chip. Distributions of CNV sizes, probe spacing, and $\log _{2}$ values were generated for gains, normal copy, and losses conditional on the observed distributions of these quantities in each sample. Using this information, normal copy and $\mathrm{CNV}$ regions were simulated for each sample across all three array platforms, and subjected to the same CNV analysis as described above. For a given region, overlapping $\mathrm{CNV}$ calls are defined in cases where the same CNV genotype is obtained between platforms.

\section{CNV allele frequency estimations}

Exact allele frequencies are difficult to calculate because precise copy numbers are unknown. To this end, we inferred approximate allele frequencies by simplifying CNV phenotypes into three categories: normal copy, gain, or loss. The frequency of each category was estimated by a standard EM algorithm [28]. The estimated allele frequencies were used to calculate expected heterozygosity $\left(\mathrm{H}_{\mathrm{e}}\right)$ for each breed and each $\mathrm{CNV}$ region as $\mathrm{H}_{\mathrm{e}}=1-\left(\mathrm{p}^{2}+\mathrm{q}^{2}+\mathrm{r}^{2}\right)$, where $\mathrm{p}, \mathrm{q}$, and $\mathrm{r}$ denote the frequencies of chromosome carrying normal copy, gains, and losses, respectively. Similarly for each CNV region, we calculated $\mathrm{F}_{\mathrm{ST}}$ as: $\mathrm{F}_{\mathrm{ST}}=1-\mathrm{h}_{\mathrm{s}} / \mathrm{h}_{\mathrm{t}}$, where $\mathrm{h}_{\mathrm{s}}$ and $\mathrm{h}_{\mathrm{t}}$ denote average heterozygosity within subpopulations (breeds) and total heterozygosity, respectively.

\section{Gene identification and PANTHER analysis}

A catalog of all canine peptides was downloaded from Ensembl ftp://ftp.ensembl.org/pub/current_fasta/canis_familiaris/pep/, which contains 25,546 peptides. For each breed, the total number of genic CNVs and associated peptides were determined and PANTHER Molecular Function terms were assigned to all peptides using the PANTHER Hidden Markov Model scoring tools http://www.pantherdb.org/downloads/. PANTHER Molecular Function terms with less than five observations among the breed associated genes were not analyzed further. For each breed, we tested for overrepresentation of PANTHER terms in the CNV regions using the hypergeometric distribution. Bonferroni corrections were used to correct p-values for multiple hypothesis testing.

\section{Additional material}

Additional file 1: Enriched Panther Molecular Function Terms in CNV regions identified on the $\mathbf{2} .1$ chip. This table summarizes Gene 
Ontology Molecular Function terms that are significantly overrepresented in CNV regions identified on the 2.1 chip.

Additional file 2: Heterozygosities of the 49 regions where one breed was fixed for a CNV that was absent in one or more breeds This table summarizes heterozygosities of the 49 CNV regions that exhibit interesting patterns of allele frequency variation within and between breeds.

Additional file 3: Summary of all CNV regions. This table provides information on the genomic locations and sources for all CNV regions.

Additional file 4: CNV genotypes. This table summarizes genotypes for all individuals across all CNVs.

\section{Acknowledgements}

We thank members of the Akey laboratory and Katrina Mealey for helpful discussions related to this work. In addition, we thank Mark Neff for DNA samples. This work was supported, in part, by an NIH grant HG002385 to E.E. E. E.E.E. is an investigator of the Howard Hughes Medical Institute.

\section{Author details}

'Department of Genome Sciences, University of Washington, 1705 NE Pacific, Seattle, WA. 98195, USA. ${ }^{2}$ Howard Hughes Medical Institute, Seattle, WA, USA

\section{Authors' contributions}

TJN, EEE, and JMA conceived of and designed the experiments. TJN and CB performed all of the experiments. TJN and JMA analyzed the data. TJN and JMA wrote the paper. All authors read and approved the final manuscript.

\section{Competing interests}

The authors declare that they have no competing interests.

Received: 10 January 2011 Accepted: 16 August 2011 Published: 16 August 2011

\section{References}

1. Karlsson EK, Baranowska I, Wade CM, Salmon Hillbertz NH, Zody MC, Anderson N, Biagi TM, Patterson N, Pielberg GR, Kulbokas EJ, Comstock KE, Keller ET, Mesirov JP, von Euler H, Kämpe O, Hedhammar A, Lander ES, Andersson G, Andersson L, Lindblad-Toh K: Efficient mapping of mendelian traits in dogs through genome-wide association. Nat Genet 2007, 39:1321-1328.

2. Kirkness EF, Bafna V, Halpern AL, Levy S, Remington $K$, Rusch DB, Delcher AL, Pop M, Wang W, Fraser CM, Venter JC: The dog genome: survey sequencing and comparative analysis. Science 2003, 39:1898-1903.

3. Lindblad-Toh K, Wade CM, Mikkelsen TS, Karlsson EK, Jaffe DB, Kamal M, Clamp M, Chang JL, Kulbokas EJ, Zody MC, Mauceli E, Xie X, Breen M, Wayne RK, Ostrander EA, Ponting CP, Galibert F, Smith DR, DeJong PJ, Kirkness E, Alvarez P, Biagi T, Brockman W, Butler J, Chin CW, Cook A, Cuff J, Daly MJ, DeCaprio D, Gnerre S, Grabherr M, et al: Genome sequence, comparative analysis and haplotype structure of the domestic dog Nature 2005, 39:803-819.

4. Akey JM, Ruhe AL, Akey DT, Wong AK, Connelly CF, Madeoy J, Nicholas TJ, Neff MW: Tracking footprints of artificial selection in the dog genome. Proc Natl Acad Sci USA 2010, 39:1160-1165.

5. Cadieu E, Neff MW, Quignon P, Walsh K, Chase K, Parker HG, Vonholdt BM, Rhue A, Boyko A, Byers A, Wong A, Mosher DS, Elkahloun AG, Spady TC, André C, Lark KG, Cargill M, Bustamante CD, Wayne RK, Ostrander EA: Coat variation in the domestic dog is governed by variants in three genes. Science 2009, 39:150-153.

6. Sutter NB, Bustamante CD, Chase K, Gray MM, Zhao K, Zhu L, Padhukasahasram B, Karlins E, Davis S, Jones PG, Quignon P, Johnson GS, Parker HG, Fretwell N, Mosher DS, Lawler DF, Satyaraj E, Nordborg M, Lark KG, Wayne RK, Ostrander EA: A single IGF1 allele is a major determinant of small size in dogs. Science 2007, 39:112-115.

7. Boyko AR, Boyko RH, Boyko CM, Parker HG, Castelhano M, Corey $L$, Degenhardt JD, Auton A, Hedimbi M, Kityo R, Ostrander EA, Schoenebeck J, Todhunter RJ, Jones P, Bustamante CD: Complex population structure in
African village dogs and its implications for inferring dog domestication history. Proc Natl Acad Sci USA 2009, 39:13903-13908.

8. Boyko AR, Quignon P, Li L, Schoenebeck JJ, Degenhardt JD, Lohmueller KE, Zhao K, Brisbin A, Parker HG, vonHoldt BM, Cargill M, Auton A, Reynolds A, Elkahloun AG, Castelhano M, Mosher DS, Sutter NB, Johnson GS,

Novembre J, Hubisz MJ, Siepel A, Wayne RK, Bustamante CD, Ostrander EA: A simple genetic architecture underlies morphological variation in dogs. PLOS Biol 2010, 8:e1000451

9. Vonholdt BM, Pollinger JP, Lohmueller KE, Han E, Parker HG, Quignon P, Degenhardt JD, Boyko AR, Earl DA, Auton A, Reynolds A, Bryc K, Brisbin A, Knowles JC, Mosher DS, Spady TC, Elkahloun A, Geffen E, Pilot M, Jedrzejewski W, Greco C, Randi E, Bannasch D, Wilton A, Shearman J, Musiani M, Cargill M, Jones PG, Qian Z, Huang W, et al: Genome-wide SNP and haplotype analyses reveal a rich history underlying dog domestication. Nature 2010, 39:898-902

10. Chen WK, Swartz JD, Rush LJ, Alvarez CE: Mapping DNA structural variation in dogs. Genome Res 2009, 39:500-509.

11. Fadista J, Nygaard M, Holm LE, Thomsen B, Bendixen C: A Snapshot of CNVs in the Pig Genome. Plos One 2008, 3:e3916.

12. Fontanesi L, Martelli PL, Beretti F, Riggio V, Dall'Olio S, Colombo M, Casadio R, Russo V, Portolano B: An initial comparative map of copy number variations in the goat (Capra hircus) genome. BMC Genomics 2010, 11:639.

13. Graubert TA, Cahan P, Edwin D, Selzer RR, Richmond TA, Eis PS, Shannon WD, Li X, McLeod HL, Cheverud JM, Ley TJ: A high-resolution map of segmental DNA copy number variation in the mouse genome. PLoS Genet 2007, 3:e3.

14. Guryev V, Saar K, Adamovic T, Verheul M, van Heesch SA, Cook S, Pravenec M, Aitman T, Jacob H, Shull JD, Hubner N, Cuppen E: Distribution and functional impact of DNA copy number variation in the rat. Nat Genet 2008, 39:538-545.

15. Kidd JM, Cooper GM, Donahue WF, Hayden HS, Sampas N, Graves T, Hansen N, Teague B, Alkan C, Antonacci F, Haugen E, Zerr T, Yamada NA, Tsang P, Newman TL, Tüzün E, Cheng Z, Ebling HM, Tusneem N, David R, Gillett W, Phelps KA, Weaver M, Saranga D, Brand A, Tao W, Gustafson E, McKernan K, Chen L, Malig M, Smith JD, et al: Mapping and sequencing of structural variation from eight human genomes. Nature 2008, 39:56-64.

16. Liu GE, Hou Y, Zhu B, Cardone MF, Jiang L, Cellamare A, Mitra A, Alexander LJ, Coutinho LL, Dell'Aquila ME, Gasbarre LC, Lacalandra G, Li RW, Matukumalli LK, Nonneman D, Regitano LC, Smith TP, Song J, Sonstegard TS, Van Tassell CP, Ventura M, Eichler EE, McDaneld TG, Keele JW: Analysis of copy number variations among diverse cattle breeds. Genome Res 2010, 39:693-703.

17. Nicholas TJ, Cheng Z, Ventura M, Mealey K, Eichler EE, Akey JM: The genomic architecture of segmental duplications and associated copy number variants in dogs. Genome Res 2009, 39:491-499.

18. Perry GH, Tchinda J, McGrath SD, Zhang J, Picker SR, Cáceres AM, lafrate AJ, Tyler-Smith C, Scherer SW, Eichler EE, Stone AC, Lee C: Hotspots for copy number variation in chimpanzees and humans. Proc Natl Acad Sci USA 2006, 39:8006-8011.

19. Salmon Hillbertz NH, Isaksson M, Karlsson EK, Hellmén E, Pielberg GR, Savolainen $\mathrm{P}$, Wade CM, von Euler $\mathrm{H}$, Gustafson U, Hedhammar A Nilsson M, Lindblad-Toh K, Andersson L, Andersson G: Duplication of FGF3, FGF4, FGF19 and ORAOV1 causes hair ridge and predisposition to dermoid sinus in Ridgeback dogs. Nat Genet 2007, 39:1318-1320.

20. Bailey JA, Kidd JM, Eichler EE: Human copy number polymorphic genes. Cytogenet Genome Res 2008, 39:234-243.

21. Conrad DF, Pinto D, Redon R, Feuk L, Gokcumen O, Zhang Y, Aerts J, Andrews TD, Barnes C, Campbell P, Fitzgerald T, Hu M, Ihm CH, Kristiansson K, Macarthur DG, Macdonald JR, Onyiah I, Pang AW, Robson S, Stirrups K, Valsesia A, Walter K, Wei J, Wellcome Trust Case Control Consortium, Tyler-Smith C, Carter NP, Lee C, Scherer SW, Hurles ME: Origins and functional impact of copy number variation in the human genome. Nature 2009, 39:704-712.

22. Sudmant PH, Kitzman JO, Antonacci F, Alkan C, Malig M, Tsalenko A Sampas N, Bruhn L, Shendure J, 1000 Genomes Project, Eichler EE: Diversity of human copy number variation and multicopy genes. Science 2010, 39:641-646.

23. Goidts V, Cooper DN, Armengol L, Schempp W, Conroy J, Estivill X, Nowak N, Hameister $\mathrm{H}$, Kehrer-Sawatzki H: Complex patterns of copy number variation at sites of segmental duplications: an important 
category of structural variation in the human genome. Hum Genet 2006, 39:270-284.

24. Perry GH, Yang F, Marques-Bonet T, Murphy C, Fitzgerald T, Lee AS, Hyland C, Stone AC, Hurles ME, Tyler-Smith C, Eichler EE, Carter NP, Lee C, Redon R: Copy number variation and evolution in humans and chimpanzees. Genome Res 2008, 39:1698-1710.

25. Redon R, Ishikawa S, Fitch KR, Feuk L, Perry GH, Andrews TD, Fiegler H, Shapero MH, Carson AR, Chen W, Cho EK, Dallaire S, Freeman JL, González JR, Gratacòs M, Huang J, Kalaitzopoulos D, Komura D, MacDonald JR, Marshall CR, Mei R, Montgomery L, Nishimura K, Okamura K, Shen F, Somerville MJ, Tchinda J, Valsesia A, Woodwark C, Yang F, et al: Global variation in copy number in the human genome. Nature 2006, 39:444-454.

26. She X, Cheng Z, Zollner S, Church DM, Eichler EE: Mouse segmental duplication and copy number variation. Nat Genet 2008, 39:909-914.

27. Rueda OM, Diaz-Uriarte R: Flexible and accurate detection of genomic copy-number changes from aCGH. PLoS Comput Biol 2007, 3:e122.

28. Dempster AP, Laird NM, Rubin DB: Maximum Likelihood from Incomplete Data Via Em Algorithm. Journal of the Royal Statistical Society Series BMethodological 1977, 39:1-38.

29. Mulnix JA, Smith KW: Hyperadrenocorticism in a dog: a case report. J Small Anim Pract 1975, 39:193-200.

30. Owens JM, Drucker WD: Hyperadrenocorticism in the dog: canine Cushing's syndrome. Vet Clin North Am 1977, 39:583-602

31. Rosser EJ, Dunstan RW, Breen PT, Johnson GR: Sebaceous Adenitis with Hyperkeratosis in the Standard Poodle - a Discussion of 10 Cases. Journal of the American Animal Hospital Association 1987, 39:341-345.

32. Scarff DH: Sebaceous adenitis in standard poodles. Vet Rec 2000, 146:476.

33. Hollox EJ, Huffmeier U, Zeeuwen PL, Palla R, Lascorz J, et al: Psoriasis is associated with increased beta-defensin genomic copy number. Nat Genet 2008, 39:23-25.

34. Li W, Wang JC: Mammalian DNA topoisomerase Illalpha is essential in early embryogenesis. Proc Natl Acad Sci USA 1998, 39:1010-1013.

35. Qi Y, Ranish JA, Zhu X, Krones A, Zhang J, et al: Atbf1 is required for the Pit1 gene early activation. Proc Natl Acad Sci USA 2008, 39:2481-2486.

36. Tagawa H, Miura I, Suzuki R, Suzuki H, Hosokawa Y, et al: Molecular cytogenetic analysis of the breakpoint region at 6q21-22 in T-cell lymphoma/leukemia cell lines. Genes Chromosomes Cancer 2002, 39:175-185.

37. Ettinger SN: Principles of treatment for canine lymphoma. Clin Tech Small Anim Pract 2003, 39:92-97.

doi:10.1186/1471-2164-12-414

Cite this article as: Nicholas et al:: A high-resolution integrated map of copy number polymorphisms within and between breeds of the modern domesticated dog. BMC Genomics 2011 12:414.

\section{Submit your next manuscript to BioMed Central and take full advantage of:}

- Convenient online submission

- Thorough peer review

- No space constraints or color figure charges

- Immediate publication on acceptance

- Inclusion in PubMed, CAS, Scopus and Google Scholar

- Research which is freely available for redistribution

Submit your manuscript at www.biomedcentral.com/submit
Biomed Central 